\title{
Use of Unmanned Aerial Vehicles (UAV) and Marine Environment Simulator in Oil Pollution Investigations
}

\author{
İrşad BAYIRHAN, Cem GAZIOĞLU \\ Institute of Marine Sciences and Management, Department of Marine Environment, \\ Istanbul University, 34134, Istanbul-Turkey \\ ibayirhan@istanbul.edu.tr, cemga@istanbul.edu.tr
}

\begin{abstract}
Oil is one of the most important substances causing marine pollution. Oil covering the sea surface damages the marine ecosystem and prevents the oxygen cycle between the sea and the atmosphere. For these reasons, the importance of protecting the marine environment against oil pollution, which is the most serious pressure on the marine environment, emerges. Recent investigations approved that UAV could provide an effective, low cost way to conduct surveillance of oil spills. Especially in emergency response applications that require rapid decision making, UAV systems can provide a wide range of perception through autonomous systems as well as generating data.

On the other hand, a number of image processing techniques and multi-functional computer programs are needed to interpret the data obtained from UAVs in terms of coastal management. Marine Environment Simulators (MES) is one of these multifunctional programs. In this study, it has been shown how UAVs and MES are used for this purpose and how this combination will increase the intervention operation in oil pollution researches. For this purpose, an integrated model proposal is presented for the use of UAV and MES in oil pollution research.
\end{abstract}

Keywords: Unmanned Aerial Vehicles, Marine Environment Simulators, oil pollution, oil spill

\section{Introduction}

In recent years, Unmanned Aerial Vehicles (UAVs) have become widespread in different application areas. Like many important developments, UAV systems, which have been used primarily for military purposes, are now widely used in civilian applications recently (Erenoğlu and Erenoğlu, 2018). Among their many uses, UAVs can be utilized for Earth observation, agriculture, environment monitoring and sampling, general scientific research, meteorology, etc. UAVs are cheaper, smaller, lighter, practical and more user friendly than all other geoinformatics observation equipment. In addition to being able to provide many different equipment as a mobile operator with economic efficiency, it is preferred by researchers due to their many other features, such as UAV's ability to provide high-resolution images without requiring large organizations in confined spaces. Recent developments and environmental entrepreneurship in UAV technology have created a new paradigm in the field of geoinformation technologies 
(Colomina et al., 2008). UAVs typically fly at low altitudes to acquire remote sensing data (Ollero and Merino, 2006; Saberioon et al., 2014). Although expectations produce advantages in the launch of a new technology, overly high expectations may have a detrimental impact on technology adoption (Freeeman and Freeland, 2015).

In addition to their advantages in hazardous conditions, UAVs provide a tool that complements other remote sensing technologies (Özdemir et al., 2014) for regional scale studies (Pinter et al., 2003) and they have other advantages including low cost, smaller dimensions, flexibility and the ability to reliably fly at low altitudes and around obstacles (Molchanov et al., 2014; Mongillo et al., 1994 and 1992; Ollero et al., 2006). It is a powerful coordination tool for the MES due to these features and its complementary aspect.

The application of UAVs has attracted great interest for disaster monitoring and sensing (Luo et al., 2015). Recent studies approved that (Marques et al., 2016 and 2015) UAV could provide an effective, low cost way to conduct surveillance of oil spills. It is of utmost importance to reduce the loss of lives primarily in the seas. Especially in emergency intervention applications that need to be decided quickly, UAV systems can generate data through operators who have been trained for a short period of time, as well as provide a wide area of perception through autonomous systems. UAV systems will be able to direct rescue teams in a short time to prevent casualties. The next important step is to ensure that the environmental impacts that may arise after the accident are taken as soon as possible. However, the limited computational capability and low energy resource of UAVs present a significant challenge to real-time data processing, networking and policy making, which are of vital importance to many disasters such as oil spill detection (Luo et al., 2015). Therefore, in this study, the suggestion of integrating with software systems with control, evaluation and response operations capabilities is emphasized in order to use UAVs more effectively in case of incident.

Oil spills and related petroleum products in the marine environment can have serious biological and economic impacts. In the event of an oil spill in the marine environment, every effort should be made by governments and other organizations to prevent oil pollution. The most effective way to do this would be to have pre-planned response operations and emergency response strategies to prevent oil spills as soon as possible. International Maritime Organization and other international maritime institutions categorizes the oil spills by size - less than 7 tones; between 7 tones and 700 tones; and more than 700 tones. Since 1967, more than 10000 accidents have been registered and from these, \%81 rank in the less than 7 tones categories. The Bonn Agreement (2004) stipulates the oil appearance code to be observed within different sensors to guarantee the presence of oil on the sea surface and to determine its category. UAV systems offer a wide range of paradigm changes to decision-makers in the context of environmental disasters and monitoring of their impacts, as well as the wide flexibility and ease of operation they provide in conditions that depend on satellite routes, time and atmosphere conditions where conventional remote sensing systems are insufficient.

In addition, advanced mathematical models are integrated with computer simulation to better predict oil behavior and to make the best decisions for intervention procedures that minimize environmental impact. For example; PISCES II (Potential Incident Simulation, Control and Evaluation System II), GNOME (General NOAA (National Oceanic and Atmospheric Administration) Operational Modeling Environment), OILMAP (Oil Spill Model and Response System) and ADIOS (Automatic Data Inquiry for Oil Spills) are computer programs that predict the rapid movement of spilled oil by 
both environmental and hydrodynamic data and determination of oil spill scenario (Aydin and Solmaz, 2019).

Convergent collection of oil and its derivatives that spread to the sea surface after shipwrecks is a primary objective in reducing the effects of environmental catastrophe. For this reason, it is necessary to calculate the thickness of the oil and its derivatives on the sea surface and to cover it with the surface (in situ) data. So far, oil spill modeling has been based on the use of simple experimental observations and formulation. Fay (1969 and 1971), Mackay et al. (1980), Lehr et al. (1984), Delvigne at al. (1988), Güven et al., (1998; 2006), Doğan et al. (1998) and Fingas et al. (1996) developed pioneering work on the physical processes involved in the spread of oil to the water surface. Recently, various model approaches using advanced technology sensation systems for oil accidents have been widely used, taking into account empirical measurements of oil spill and theoretical physical processes (Şeker et al., 2013; Papila et al., 2018; Abdikan et al., 2018; Gazioğlu et al., 2016, 2017; Gazioğlu, 2018).

For this purpose, in this study firstly, the ability of UAVs to event notification and how MESs will use this notice for analysis and the most effective response is discussed. Then, an integrated model proposal is presented for the use of UAV and MES in oil pollution research.

\section{Combination of UAV and MES}

Remote sensing is detected in a wide spectrum, from oil spills detection to tracking and mapping, from the simplest imaging techniques to radar images. However, generic offthe-shelf sensors still have very limited application to oil spills. Radar is a technology that has proven itself indisputably in satellite images of oil spills and pollution investigations for large areas and it is one of the few sensors that can 'see' at night and through clouds or fog. Unfortunately, oil slicks are not the only phenomena that are detected only Radar technology which can be effective in open seas could not provide sufficient results especially in shallow and narrow regions, in marine environments where wave crushing or irregular wave regime is dominant. Besides, the first intervention in the oil spills is very important. The shape, direction and speed of the intervention, especially in the off-shore region, have a decisive influence on final success. At this point, software based on mathematical modeling of an oil spill in the marine environment is vital in the response phase. Such a simulation program predicts the behavior of an oil spill in the water based on spill parameters, the type of oil source and post-spill environmental conditions in a highly functional manner. In addition, some programs at sea are possible to manage the response operations in real time.

The use of visible spectrum alone is not considered remote sensing, however still forms the most common technique for oil spill surveillance. Optical techniques are the most common means of remote sensing. In recent years, optical sensors could contribute significantly to the generation of situational maritime awareness, and particularly in environmental protection like the detection of maritime oil spills using by UAVs. Oil generally manifests throughout this visible spectrum. Overall, however, oil has no specific characteristics that distinguish it from the background. By adjusting the camera to a specific angle, high contrast can be obtained on the image that is perceived from the visible region using a horizontally aligned polarizing filter that passes the reflected light from the water surface only. 


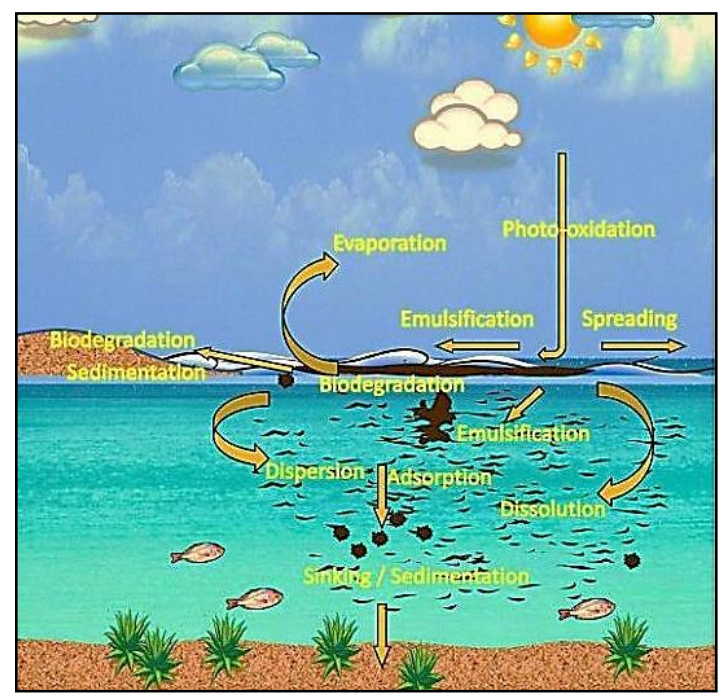

Figure1. Weathering processes (McGenity et al., 2012)

This image and environmental data (air and water temperatures, wind direction and speed, sea state, the density of water and surface current) obtained are manually placed in the model. Because, in many models, it is aimed to control oil behavior and condition in the marine environment. The conditions of the spilled oil will change over time in both surface and water column of sea. Therefore, the physical, chemical and decomposition process of the oil should be well known when showing the estimated behavior of the oil spill (ITOPF, 2002). Oil spill in the marine environment generally takes place in two directions, horizontally and vertically. It occurs as a spread in the horizontal direction and causes the surface to be coated with oil or hit the shore. Vertical movement occurs when the oil is dispersed or dissolved in the sea, and as time passes, the oil sinks to the bottom and becomes part of the sediment at the bottom. In general, the oil weathering process (spreading, emulsification, evaporation, dispersion, photooxidation, adsorption, biodegradation, dissolution and sinking/sedimentation) are processes when exposed to environmental conditions in the marine ecosystem, as shown in Fig. 1 (McGenity et al., 2012). Each weather process occurs at different rates and times in parallel with ambient conditions.

When oil enters the marine environment and starts to spread, they usually come to the surface. The amount of oil spilled and the viscosity affect the rate of spread over the sea (ITOPF, 2002). Other important variables in oil spill are wind and current effects (Hault, 1972; Fingas, 2013).

All these parameters and potential UAV data are the inputs that MES need to create accident scenarios. Parameters should be indicated in major headings; determination of accident impact area, determination of environmental conditions, pollution parameters and response resources are the most important inputs. MES are particularly important for coordinators managing the response process. The simulation program has the great advantages in documenting pollution / spill statistics, the amount of stranded oil on the coastline, the time to reach the shore, and the efficiency ratio of the response equipment. 


\section{UAV-MES Simple Integration Test}

The main motivation for this study is a recent marine accident. The prototype of the system used in this study was used to provide instantaneous data flow to decision making mechanisms in the accident that occurred in the anchorage location at the Black Sea entrance of the Istanbul Strait (Bosphorus), during field research and intervention coordination. In this accident where the ship named Orcun $\mathrm{C}$ was stranded on 19.01.2010, although it changes from place to place, the shores of Istanbul Kilyos were covered with a thick mixture of petroleum and oil.

Before the response operations, UAV survey was used to identify and analyze the crash site for the first time in Turkey. UAV has been aired up to 300 meters above the sea. The exact coordinates of the accident site and the oil spill area were determined in as short as 15 minutes. In the Kilyos region, a response team of about 200 people surrounded the coast halfway on the two shores of Bora Bay, thereby preventing a larger environmental disaster. In this case, it is understood how fast UAVs can change their working parameters in regions where environmental conditions are very difficult. And it has increased the reliability of UAV use in such marine accidents.

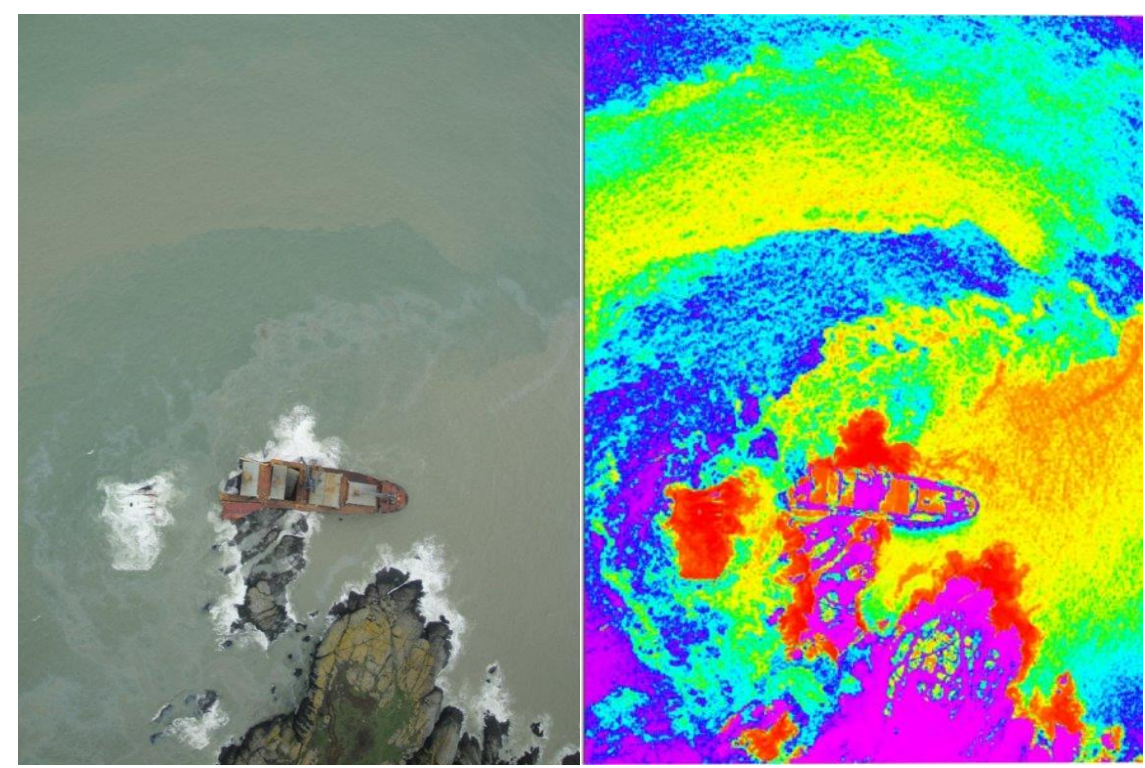

Figure 2. 21.01.2010 Orcun C accident in Kilyos/Istanbul

The first of the images shown in the Fig. 2 is the image of the accident area taken from the UAV and the output showing the oil spill by in situ image processing. However, the detection of the oil spill by the image processing techniques of the UAV image provides only one prediction and is insufficient to create data for response operations. In other words, the data obtained from the UAV should be more functional, such as making it qualified to combat oil pollution and providing operators with scenarios regarding the possible behavior (direction, speed, depth) of oil spill. The platform that can provide these functions is MES. 
A simple accident scenario was created on 22.07.2019 for this structure, which further functionalizes the use of MES against oil pollution, and the UAV-MES combination was tested. Snapshots taken with the UAV (DJI Phantom 3 Pro 4k v2 Drone) ventilated at Istanbul / Fatih district Balat estuary beach were transferred to GNOME (NOAA) MES software. Fig. 3 shows the menu for adding location to GNOME (NOAA) MES software. At this point, the efficiency of the pre-intervention process, which started with rapid arrival at the scene after the accident notification, was also tested. UAV images are assumed as accident images and connected to the map insertion tool on the software.

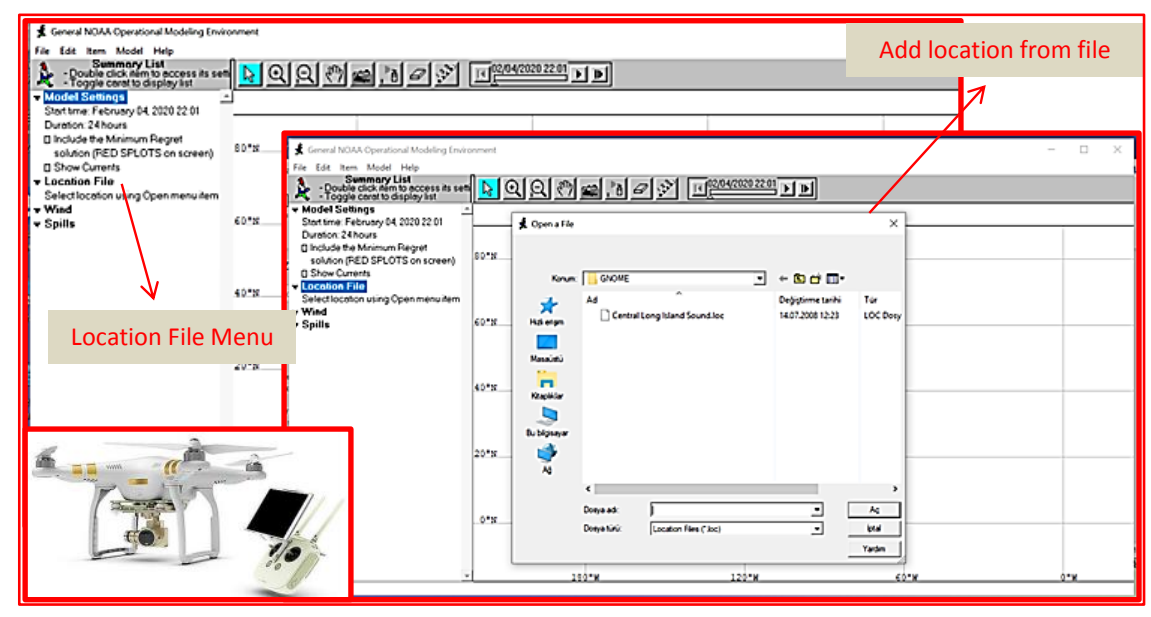

Figure 3. GNOME (NOAA) MES software and location screen

According to the coordination of the event area, the weather and sea report information was provided, and a scenario was created as if there was indeed a spill of oil in a sea accident at that time. In this case, the expected outputs are the identification of the correct points to prevent environmental pollution in addition to a series of technical information such as flow direction, collapse or evaporation rate. In addition, the capacity to answer questions such as the number of equipment and teams needed, and what other factors it needs is tested. Of course it is pointless to wait for a real accident to test such a system. In fact, it is more important to fully establish the pre-accident working infrastructure in order to obtain correct results. Therefore, the main methodology of the study is not the field test, but the creation of the working principle.

\section{Results and Discussion}

For an efficient and harmonious working system, all parameters described up to this point must be input correctly on the system. In this study, an integrated model is proposed for the use of UAV and MES in oil pollution researches. The model in question is shown in Fig. 4.

In the process that starts with an event notification in the model, the notice is evaluated and a distinction is made whether there is an accident or an incident. For a 
certain assessment, advanced UAVs for accident investigations have to verify and monitor the event. The data obtained are then transferred to the MES associated with the coastal management system. These multi-functional simulators provide output on possible environmental risks of the accident and response operations to prevent oil spill. There are various variations of response operations scenarios within the system outputs.

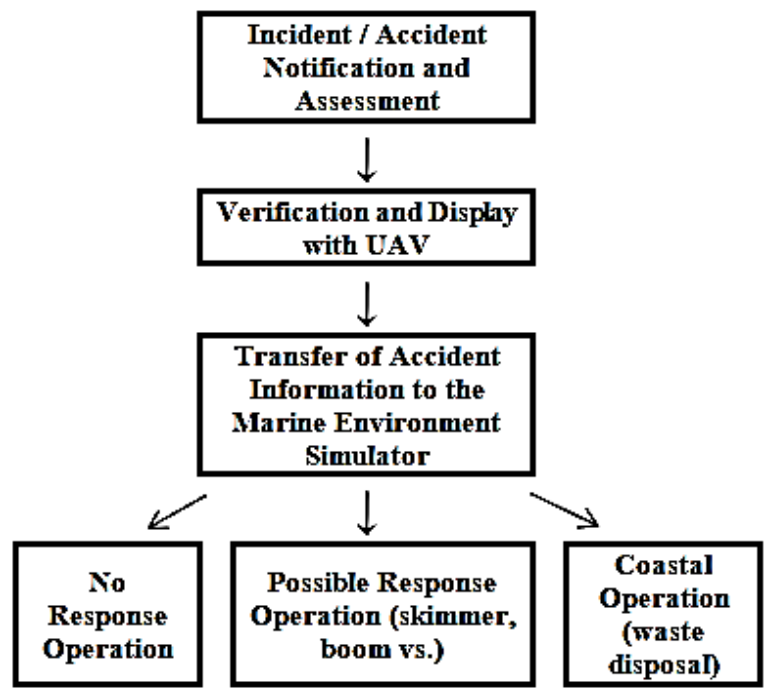

Figure 4. Combination models of UAV and MES

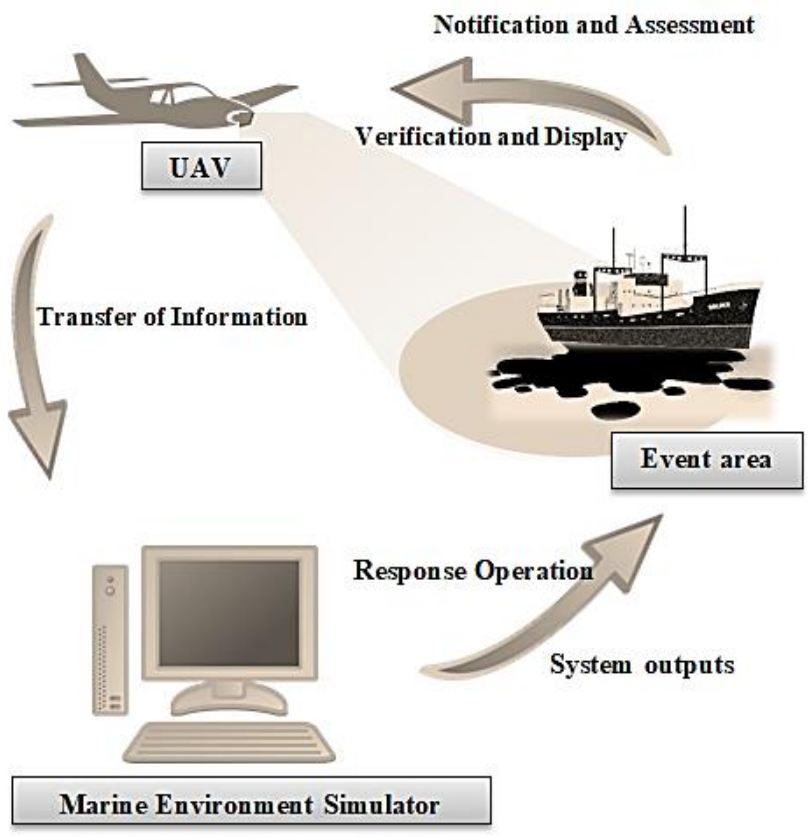

Figure 5. Integrated working principle of UAV and MES 
The UAV, which is activated by controlling from the nearest land or marine station to the event area specified in Fig. 5, collects the necessary visual data about the event. Of course, only one image-driven UAV is sufficient for the operating principle of the model, but the use of sensors sensitive to oil spill will provide additional benefits at this stage.

Moreover, an advanced image processing program can be added to this stage of the model when a more functional structure is desired In this study, UAVs are in the concept of a notification tool and instant information source, which are integrated with MES which, receives incident information from the UAV about the oil spill, provides the necessary environmental data from the relevant local authorities according to the coordinates of the event area.

Some software serve the simulator program with a connection structure in which seawater quality and meteorological data are automatically imported into the system. Therefore, it is very important that the UAVs accurately determine the coordinates of the event area in order to provide accurate environmental data input to the system. The simulator software then creates scenarios for oil spill, speed and direction, taking into account all the conditions at the scene of the accident. The amount and direction of oil spill over various time intervals following the accident is particularly important for a correct response operation method. Accordingly, the system finally provides the output of the variations of the response arguments, how the timing should be and in which direction it should be used. The system specifies how the skimmer and booms should be placed and what their quality should be, on behalf of the coastal management authority responsible for response to the accident. With all these outputs, the amount and location of the material required for disposal is also an important result of the system.

\section{Conclusion}

The prevention and response of oil pollution in marine accidents consists of a series of procedures. In this study, how UAVs and MES are used for this purpose and how this combination will increase safety measures and efficiency of response operations in oil pollution researches are investigated. Therefore, an integrated model proposal for the use of UAV and MES in oil pollution research is presented. For an efficient and harmonious working system, the most important inputs such as accident impact area, environmental conditions, pollution parameters and response resources must be placed in the system correctly. As a result, the proposed integrated model provides a clear usefulness for a real case, although it is in a status dependent on the hypothetical parameters of any event occurring at sea. Especially, it will be useful to establish this system in waterways close to the densely populated settlements, in narrow passages, canal and strait, in areas where oil transportation is dense. In such sensitive areas, the most accurate decision and speed in the accident response management is vital for the responsible coastal authority.

The use of three-dimensional oil distribution models for MES, which are specialized in petroleum distributions instead of two-dimensional surface dispersion models, and that contain specialized complex algorithms for evaporation and chemical conversions, will enable systems to become an advanced decision support system not only in administrative but also ecologically. 


\section{References}

Abdikan, S., Bayık, Ç., Balık Şanlı, F. (2018). The Role of Sar Remote Sensing To Detect Oil Pollution And Emergency Intervention, Ünlü, S., Alpar, B., Öztürk, B. (Eds) (2018). Oil Spill along the Turkish Straits Sea Area; Accidents, Environmental Pollution, SocioEconomic Impacts and Protection. Turkish Marine Research Foundation (TUDAV), Publication No 47, İstanbul, Turkey, 157-175.

Aydın, D., Solmaz, M. S. (2019). Modelling of the Oil Spill in M/V Lady Tuna Accident and the Evaluation of the Response Operation in Simulated Condition with PISCES II. International Journal of Environment and Geoinformatics (IJEGEO), Vol. 6(2): 213-224.

Bonn Agreement (2004). Bonn Agreement, Aerial Surveillance Handbook 2004.

Colomina, I., Blázquez, M., Molina, P., Parés, M., Wis, M. (2008). Towards a new paradigm for high-resolution low-cost photogrammetry and remote sensing, ISPRS - Int. Arch. Photogramm. Remote Sens. Spatial Inform. Sci., XXXVII-B1: 1201-1206.

Delvigne, G. A. L., Sweeney, C. E. (1988). Natural dispersion of oil. Oil and Chemical Pollution, 4(4), 281-310. Doi:10.1016/S0269-8579(88)80003-0

Doğan, E., C. Gazioğlu, E. Okuş, I.E. Gönenç, H. Yüce., ZY. Yücel. (1998). Examination of the Pollution in the West Black Sea by Remote Sensing Technologies, Journal of Black Sea/Mediterranean Environment, 4(2), 89-101.

Erenoğlu, R, Erenoğlu, O. (2018). A case study on the comparison of terrestrial methods and unmanned aerial vehicle technique in landslide surveys: Sarıcaeli landslide, Çanakkale, NW Turkey. International Journal of Environment and Geoinformatics, 5 (3), 325-336. DOI: 10.30897/ijegeo.468061

Fay, J.A. (1969). The spread of oil slicks on a calm sea. In D. P. Hoult (Ed.), Oil on the Sea, 5363. New York.

Fay, J.A. (1971). Physical processes in the spread of oil on a water surface. Proceedings of the Joint Conference on Prevention and Control of Oil Spills, American Petroleum Institute, Washington D. C., 463-467.

Fingas, M., Fieldhouse, B., Mullin, J. (1996). Studies of water-in-oil emulsions: the role of asphaltenes and resins, Proceedings of the Nineteenth Arctic and Marine Oil spill Program (AMOP) Technical Seminar, Environment Canada, Emergencies Science Division, Ottawa, Ontario, Canada.

Fingas, M.F. (2013). Modeling oil and petroleum evaporation. Journal of Petroleum Science Research, 2 (3), 104-115.

Freeman, P.K., Freeland, R.S. (2015). Agricultural UAVs in the U.S.: potential, policy, and hype, Remote Sensing Applications: Society and Environment, Vol.2:35-43.

Gazioğlu, C., Akkaya, M.A., Baltaoğlu, S., Burak, SZ. (2016). ICZM and the Sea of Marmara: the İstanbul Case. Ed. Özsoy, E., Çağatay, M.N., Balkıs, N., Balkıs Çağlar, N., Öztürk, B., The Sea of Marmara: Marine Biodiversity, Fisheries, Conservations and Governance, 935-957.

Gazioğlu, C., Ö.E. Varol, D.Z. Şeker, N. Çağlar. (2017). Determination of the Environmental Impacts of Marine Accidents Using UAV and RS Technologies, Proceedings of $19^{\text {th }}$ MESAEP Symposium on Environmental and Health Inequity, Roma, Italy, 3-6 Dec 2017.

Gazioğlu, C. (2018). Biodiversity, coastal protection, promotion and applicability investigation of the ocean health index for Turkish seas. International Journal of Environment and Geoinformatics (IJEGEO). 5(3), 353-367.

Güven, K.C., E. Okuş, H.İ. Sur, C. Gazioğlu, A. Yüksek, S. Ünlü, H. Altıok, S. Tas, A.E. Müftüoğlu, N. Yılmaz, A. Aslan Yılmaz, Ü. Karhan., A. Yalçın (2006). Petroleum pollution of Volgoneft-248 tanker accident in the Florya-Küçükçekmece area. Final Report. Istanbul University, Institute of Marine Sciences and Management, Istanbul, Turkey.

Güven KC, Ünlü S, Bildaci I, Doğan E. (1998). An Investigation on the Oil Pollution of the Eastern Mediterranean Coast of Turkey, Turkish Journal of Marine Sciences 4:51-60.

Hault, D.P. (1972). Oil spreading on the sea, Annual Review of Fluid Mechanics, 4: 341-368.

ITOPF, (2002). Fate of marine oil spills, Technical Information Paper, Retrieved 05.10.2019 from http://www.itopf.com/knowledgeresources/documents-guides/document/tip-2-fate-of-marine 
Lehr, W.J., Fraga, R.J., Belen, M.S., Cekirge, H.M., (1984). A new technique to estimate initial spill size using a modified fay-type spreading formula. Marine Pol. Bulletin, 15(9), 326-329.

Luo, CB., Nightingale, J., Asemota, E., Grecos, C., (2015). A UAV-Cloud System for Disaster Sensing Applications, Proceedings of 81st IEEE Vehicular Technology Conference (VTC Spring), Univ Strathclyde, Technol Innovat Ctr, Glasgow, Scotland, 11-14 May 2015

Mackay, D., Buistt, I.A., Marcarenhas, R., Paterson, S. (1980). Oil spill processes and models. Environment Canada Manuscript Report No. EE-8, Ottawa, Ontario.

Marques, MM., Dias, P., Santos, N., Lobo, V., Batista, R., Salgueiro, D., Ribeiro, R., Marques, J., Bernardino, A., Griné, M., Taiana, M., Nunes, M., Pereira, E., Morgado, J., Aguiar, A., Costa, M., Silva, J., Ferreira, A., Sousa, J. (2015). Unmanned Aircraft Systems in Maritime Operations: Challenges addressed in the scope of the SEAGULL project, in MTS/IEEE Oceans, 1-6.

Marques, MM., Lobo, V., Nunes, MD., Batista, R., Almeida, J., Ribeiro, R., Bernardino, A. (2016). Oil Spills Detection: Challenges addressed in the scope of the SEAGULL project, Oceans, MTS/IEEE Monterey, Proceedings of MTS/IEEE Oceans Conference, Monterey, CA, 19-23 September 2016

McGenity, T. J., Folwell, B. D., McKew, B. A., Sanni, G. O. (2012). Marine crude-oil biodegradation: a central role for interspecies interactions. Aquatic Biosystems, 8(1), 10.

Molchanov P., R.I.A. Harmanny, J.J.M. de Wit, K. Egiazarian, J. Astola,. (2014). Classification of small UAVs and birds by micro-Doppler signatures, Int. J. Microw. Wirel. Technol. 6 Special Issue 3(4), 435-444.

Mongillo, M.A., C.J. Bromley, (1992). A helicopter-borne video thermal infrared survey of the rotorua geothermal field, Geothermics, 21(12), 197-214.

Mongillo, M.A. (1994). Aerial thermal infrared mapping of the Waimangu-Waiotapu geothermal region, New Zealand, Geothermics 23(56), 511-526.

Ollero, A., Merino, L., (2006). Unmanned aerial vehicles as tools for forest-fire fighting, For. Ecol. Manage. 234(1), 263.

Özdemir U., Y. Aktas, A. Vuruskan, Y. Dereli, A. Tarhan, K. Demirbag, A. Erdem, G. Kalaycioglu, I. Ozkol, G. Inalhan, (2014). Design of a Commercial Hybrid VTOL UAV System, J. Intell. Robot. Syst. 74(12), 371-393.

Papila, İ., Sertel, E., Kaya, Ş., Gazioğlu, C. (2018). Oil Spill Detection Using Remote Sensing Technologies- Synthetic Aperture Radar (SAR), Ünlü, S., Alpar, B., Öztürk, B. (Eds) (2018). Oil Spill along the Turkish Straits Sea Area; Accidents, Environmental Pollution, Socio-Economic Impacts and Protection. Turkish Marine Research Foundation (TUDAV), Publication No: 47 İstanbul, Turkey, 140-156.

Pinter Jr, P. J., Hatfield, J. L., Schepers, J. S., Barnes, E. M., Moran, M. S., Daughtry, C. S., Upchurch, D. R. (2003). Remote sensing for crop management. Photogrammetric Engineering \& Remote Sensing, 69(6), 647-664.

Saberioon, M.M., Amin, M.S.M., Anuar, A.R., Gholizadeh, A., Wayayok, A., Khairunniza-Bejo, S., (2014). Assessment of rice leaf chlorophyll content using visible bands at different growth stages at both the leaf and canopy scale. Int. J. Appl. Earth Obs. Geoinf. 32, 35-45.

Şeker, DZ., Direk, Ş., Musaoğlu, N., Gazioğlu, C. (2013). Determination of effects of coastal deformation caused by waves and storms at Black Sea coast of Turkey utilizing InSAR technique, AGU Fall Meeting Abstracts, Dec. 2013.

Received April 15, 2020, accepted April 18, 2020 as a paper from ISAG2019 